\title{
Effect of noradrenaline on circulation in the genital tract of early and late pregnant guinea-pigs
}

\author{
Lena Mårtensson* and A. M. Carter \\ Department of Physiology, University of Odense, Campusvej 55, DK-5230 Odense, Denmark, \\ and ${ }^{*}$ Department of Zoophysiology, University of Lund, Helgonavägen 3B,S-22362 Lund, \\ Sweden
}

\begin{abstract}
Summary. Noradrenaline infusions were given to anaesthetized guinea-pigs in early (19-23 days) and near-term (61-66 days) pregnancy. Radioactive microspheres (15 $\mu \mathrm{m})$ were used to determine blood flow in various regions of the genital tract. In late gestation, a 10-min intravenous infusion of $1 \mu \mathrm{g}$ noradrenaline $/ \mathrm{min} / \mathrm{kg}$ elicited moderate increases in vascular resistance that were counteracted by the pressor response. Uterine and placental blood flow remained unchanged, although there was a $27 \%$ decrease in perfusion of the uterine cervix and a fall of $19 \%$ in vaginal blood flow. In early pregnant guinea-pigs, blood pressure rose but vascular resistance was unaffected, resulting in an augmentation of placental blood flow. During infusion of $10 \mu \mathrm{g}$ noradrenaline $/ \mathrm{min} / \mathrm{kg}$, the vasoconstrictor response in late pregnancy was accentuated, and a strong decrease in tissue perfusion was noted in the placenta $(-36 \%)$, uterine horns $(-39 \%)$, cervix $(-70 \%)$ and vagina $(-56 \%)$. At the higher rate of noradrenaline infusion, vascular resistance also increased in the genital tract of early pregnant animals, although to a lesser extent than in late pregnancy. The results indicate an enhancement of the vasoconstrictor response to circulating catecholamines in near-term pregnancy.
\end{abstract}

\section{Introduction}

In the guinea-pig, extensive changes in uterine innervation occur during pregnancy. The uterine content of noradrenaline falls from about Day 15 onwards, reaching near zero levels at term (Owman, Rosengren, Sjöberg \& Thorbert, 1975). Simultaneously, there is a decrease in the density of fluorescent adrenergic nerve fibres in the myometrium (Bell \& Malcolm, 1978; Thorbert, Alm, Owman, Sjöberg \& Sporrong, 1978) and in the uterine concentration of tyrosine hydroxylase (Alm, Björklund, Owman \& Thorbert, 1979). Although these changes extend to the blood vessels (Bell \& Malcolm, 1978), it is not known whether they are accompanied by any alteration in vascular sensitivity to circulating endogenous and exogenous catecholamines. The extrinsic arteries, which make an important contribution to uterine vascular resistance in the guinea-pig (Moll \& Künzel, 1971), constrict after intra-arterial injection of noradrenaline late in gestation (Egund \& Carter, 1980).

The present study was undertaken to resolve whether the uterine vascular response to circulating catecholamines, exogenously administered, changes between early pregnancy and term. Attention was given to the possibility of a differentiated effect upon the uterine and placental vasculatures. The study also included the vagina, which retains its adrenergic 
innervation in pregnancy (Bell \& Malcolm, 1978), and the cervical region of the uterus, where some adrenergic nerves persist into late gestation (Thorbert et al., 1978).

\section{Materials and Methods}

Guinea-pigs obtained from Statens Seruminstitut, Copenhagen, and mated in our laboratories were studied at two stages of pregnancy: 13 animals were in early gestation (mean 21 days, range 19-23 days) with a mean body weight of $0.75 \pm 0.02 \mathrm{~kg}$, whilst 14 were in the last third (mean 63 days, range 61-66 days) and weighed $1.12 \pm 0.04 \mathrm{~kg}$. The animals were given noradrenaline intravenously at infusion rates of $1.0 \mu \mathrm{g} / \mathrm{min} / \mathrm{kg}$ (low dose) or $10.0 \mu \mathrm{g} / \mathrm{min} / \mathrm{kg}$ (high dose). The drug was dissolved in $2.5 \%$ dextrose and $0.45 \% \mathrm{NaCl}$ immediately before the intended infusion to prevent oxidation. The concentration of the drug was adjusted and the vehicle was administered at the same rate $(0.106 \mathrm{ml} / \mathrm{min})$ in all experiments.

Anaesthesia was initiated and maintained by i.p. pentobarbitone sodium. The animal was handled and surgically prepared as previously described (Sjöquist, Bjellin \& Carter, 1977; Mårtensson, Sjöquist, Bjellin \& Carter, 1979) except that artificial ventilation was avoided. A polyethylene catheter (o.d. $0.96 \mathrm{~mm}$; i.d. $0.58 \mathrm{~mm}$ ) was introduced into the right common carotid artery and its tip advanced into the left ventricle of the heart. It was subsequently used to introduce microspheres into the systemic circulation. Catheters were also inserted into a jugular vein, for the infusion of noradrenaline, and into both femoral arteries. One femoral catheter was used to sample arterial blood (see below) and the other was connected to an electromanometer to register arterial blood pressure and heart rate throughout the experiment.

Approximately $1.5 \mathrm{~h}$ after the initial dose of anaesthetic, $0.7 \mathrm{ml}$ blood was withdrawn from the carotid artery for analysis of $\mathrm{PO}_{2}, \mathrm{So}_{2}, \mathrm{PCO}_{2}$ and $\mathrm{pH}$ : the values in early and late pregnancy (mean \pm s.e.m.) were $10.9 \pm 0.39 \mathrm{kPa}(82 \pm 2.9 \mathrm{mmHg}), 99 \pm 0.6 \%, 4.7 \pm 0.12 \mathrm{kPa}(35 \pm 0.9$ $\mathrm{mmHg})$ and $7.48 \pm 0.01$, and $8.1 \pm 0.49 \mathrm{kPa}(61 \pm 3.7 \mathrm{mmHg}), 88 \pm 2.9 \%, 4.7 \pm 0.15 \mathrm{kPa}$ $(35 \pm 1.1 \mathrm{mmHg})$ and $7.44 \pm 0.02$ respectively. In a second blood sample, withdrawn at the end of the noradrenaline infusion, these values were unaltered.

Immediately following the first blood gas analysis, 600000 microspheres labelled with ${ }^{141} \mathrm{Ce}$ (size $14.8 \pm 0.9 \mu \mathrm{m}$; 3M Co., St Paul, Minnesota, U.S.A.) were slowly injected into the left ventricle while a reference sample of blood was withdrawn at a constant rate of $0.75 \mathrm{ml} / \mathrm{min}$ from the femoral artery, to determine initial blood flows and cardiac output (Mårtensson et al., 1979). The microsphere suspension was agitated throughout the injection which lasted for $45 \mathrm{sec}$ and blood was withdrawn from $15 \mathrm{sec}$ before the injection until $15 \mathrm{sec}$ afterwards. Immediately after this procedure, an intravenous infusion of 1.0 or $10.0 \mu \mathrm{g}$ noradrenaline $/ \mathrm{min} / \mathrm{kg}$ was started. After approximately $10 \mathrm{~min}$, when the maternal blood pressure had restabilized, a second determination of blood flow and cardiac output was made by injecting 525000 microspheres labelled with ${ }^{85} \mathrm{Sr}$ (size $15 \cdot 1 \pm 1 \cdot 1 \mu \mathrm{m}, 3 \mathrm{M} \mathrm{Co}$.).

Each animal was killed by an overdose of pentobarbitone sodium and the kidneys, lungs, brain, ovaries, vagina and gravid uterus were removed. The fetuses were weighed to check the stage of pregnancy (Draper, 1920) and then discarded. The placentas and their basal decidua were dislodged by blunt dissection through the normal zone of separation. The remainder of the uterine tissue was further divided in the manner suggested by Thorbert et al. (1978). In early pregnancy, the uterine tissue adjacent to the fetus (perifetal uterus) was separated from that between the conceptuses (parafetal uterus). The latter samples tended to be small especially when the litters were large. The cervical region was treated separately at both stages of gestation. In addition, a small piece of tissue was removed from the tubal end of each horn (see Thorbert $e t$ al., 1978); these samples contained too few microspheres $(<400)$ to give reliable calculations of blood flow (Buckberg et al., 1971) and they are not included in Tables 1 and 2 . The tissue samples were weighed and the radioactivity in the organs and reference samples of blood was 
measured in a gamma spectrometer $(7.7 \mathrm{~cm}$ well crystal, multichannel analyser). The height of each tissue sample in the counting vials was restricted to $10 \mathrm{~mm}$ to minimize geometric errors. The position of the catheter through which the microspheres had been injected was checked by dissecting the heart. Even distribution of microspheres in the arterial blood was confirmed by comparing blood flows to the right and left kidneys (correlation coefficient 0.99 ) and right and left halves of the brain (correlation coefficient 0.95 ). The fraction of cardiac output reaching the lungs was no more than $7 \%$, indicating that the microspheres had been effectively trapped in the capillary beds with little recirculation. The blood flow of each tissue before and during the catecholamine infusion was calculated from its content of ${ }^{141} \mathrm{Ce}$ and ${ }^{85} \mathrm{Sr}$, respectively, by solving the equation: organ blood flow/activity in organ = rate of withdrawal of reference sample/ activity in reference sample. Vascular resistance was then estimated as the ratio between mean arterial blood pressure and organ blood flow. Cardiac output was determined according to the method of Towell \& Liggins (1976) using the formula: cardiac output/total activity of injectate $=$ rate of withdrawal of reference sample/activity of reference sample.

In the text and tables all values are expressed as means \pm s.e.m. The significance of alterations in organ blood flow and vascular resistance was assessed by Student's $t$ test for dependent observations. The significance of differences between the two stages of pregnancy was examined using a $t$ test for independent observations.

\section{Results}

\section{Cardiovascular response to noradrenaline infusion}

The cardiovascular effects of noradrenaline have been well documented and are described only briefly. When the smaller dose of noradrenaline was infused, the cardiac output rose from $136 \pm 14$ to $186 \pm 12 \mathrm{ml} / \mathrm{min}(P<0.01)$ in early pregnancy and from $144 \pm 8$ to $163 \pm 9$ $\mathrm{ml} / \mathrm{min}(P<0.05)$ in late pregnancy. These changes reflect significant increases in stroke output at both stages of pregnancy, while maternal heart rate was unchanged. Mean arterial blood pressure was recorded in 5 of the 7 early pregnant animals and rose from $7.2 \pm 0.4$ to $8.6 \pm 0.3$ $\mathrm{kPa}(P<0.01)$. In late gestation $(\mathrm{N}=8)$ the increase was from $5.5 \pm 0.4$ to $6.9 \pm 0.6 \mathrm{kPa}$ $(P<0.01)$.

When a 10-fold larger dose of noradrenaline was infused there was an accentuation of the pressor response. In early pregnancy mean arterial blood pressure rose from $7.6 \pm 0.7$ to $10.0 \pm 0.4 \mathrm{kPa}$, and in late pregnant females it increased from $5.8 \pm 0.7$ to $9.6 \pm 0.7 \mathrm{kPa}$ $(P<0.01)$. Cardiac output increased in early $(122 \pm 6$ to $204 \pm 10 \mathrm{ml} / \mathrm{min}: P<0.001)$ and late $(173 \pm 18$ to $225 \pm 16 \mathrm{ml} / \mathrm{min}: P>0.05)$ pregnant animals. At both stages of gestation heart rate rose during noradrenaline infusion by $11-13 \%$. In the late gestation group, one animal deviated from the general trend, with a fall in heart rate, stroke output and cardiac output, but is included in Tables 1 and 2.

\section{Blood perfusion during noradrenaline infusion}

Responses of the ovarian, uterine, vaginal and placental vasculature to the infusion of 1 or $10 \mu \mathrm{g}$ noradrenaline $/ \mathrm{min} / \mathrm{kg}$, respectively, are presented in Table 1 . In addition to calculating mean blood flows, the percentage changes in organ blood flow and vascular resistance were determined in each experiment and have been averaged to obtain the data shown in the right-hand columns.

The initial perfusion rates for late gestational guinea-pigs were of the same magnitude as previously obtained with the same size of microspheres under similar experimental conditions (Mårtensson et al., 1979). Comprehensive data on blood flows in the reproductive tissues of early pregnant guinea pigs are not available. 
The lower dose of noradrenaline evoked a significant increase in vaginal and cervical vascular resistance in late gestation, resulting in a fall of blood flow to these tissues (Table 1). In the uterus and placentas the change in resistance was more moderate, and counterbalanced the rise in arterial pressure, so that there was no change in blood flow. Early in gestation, this dose of noradrenaline was without effect on vascular resistance, and consequently there was a tendency for blood flow to increase. Perfusion of the placentas, ovaries and parafetal uterus increased significantly. There was a significant separation between the blood flow responses in early and late gestation for the placentas $(P<0.01)$, cervix $(P<0.05)$ and vagina $(P<0.05)$, and between the parafetal uterus in early pregnancy and the entire uterus in late pregnancy $(P<$ 0.05 ) (independent $t$ tests).

Table 1. Blood flow and vascular resistance in the genital tract of pregnant guinea-pigs before and during infusion of noradrenaline $(\mathrm{A}, 1.0 \mu \mathrm{g} / \mathrm{min} / \mathrm{kg} ; \mathrm{B}, 10 \mu \mathrm{g} / \mathrm{min} / \mathrm{kg})$

\begin{tabular}{|c|c|c|c|c|c|}
\hline \multirow[b]{2}{*}{ Organ } & \multirow[b]{2}{*}{ Weight (g) } & \multicolumn{2}{|c|}{ Blood flow $(\mathrm{ml} / \mathrm{min} / \mathrm{g})$} & \multirow{2}{*}{$\begin{array}{l}\text { Mean change in } \\
\text { blood flow }(\%)\end{array}$} & \multirow{2}{*}{$\begin{array}{l}\text { Mean change in } \\
\text { resistance (\%) }\end{array}$} \\
\hline & & Control & Noradrenaline & & \\
\hline \multicolumn{6}{|c|}{ A. Late gestation $(\mathrm{N}=8)$} \\
\hline Placentas & $16 \cdot 72 \pm 1.04$ & $1.00 \pm 0.16$ & $1.01 \pm 0.16$ & $+1 \cdot 5$ & +25 \\
\hline Entire uterus & $11.88 \pm 0.63$ & $0.10 \pm 0.01$ & $0.10 \pm 0.01$ & $-1 \cdot 5$ & +31 \\
\hline Uterine horns & $11.03 \pm 0.56$ & $0.09 \pm 0.01$ & $0.09 \pm 0.01$ & $+6 \cdot 4$ & +23 \\
\hline Uterine cervix $\$ \oplus$ & $0.61 \pm 0.05$ & $0.35 \pm 0.05$ & $0.24 \pm 0.04$ & $-26 \cdot 9^{* *}$ & $+86^{* *}$ \\
\hline Ovaries & $0.13 \pm 0.01$ & $1.29 \pm 0.16$ & $1.40 \pm 0.07$ & $+16 \cdot 6$ & +5 \\
\hline Vagina & $0.92 \pm 0.09$ & $0.42 \pm 0.05$ & $0.32 \pm 0.04$ & $-18 \cdot 9^{*}$ & $+67^{*}$ \\
\hline \multicolumn{6}{|c|}{ Early gestation $(\mathrm{N}=7)$} \\
\hline Placentas & $2.34 \pm 0.21$ & $0.13 \pm 0.03$ & $0.18 \pm 0.03$ & $+54 \cdot 7^{* *}$ & $-21 \S$ \\
\hline Entire uterus & $1.87 \pm 0.11$ & $0.42 \pm 0.08$ & $0.48 \pm 0.06$ & $+21 \cdot 8$ & $-4 \S$ \\
\hline Uterine horns & $1.42 \pm 0.09$ & $0.43 \pm 0.09$ & $0.49 \pm 0.07$ & $+25 \cdot 1$ & $-7 \S$ \\
\hline Perifetal uterus & $1.14 \pm 0.07$ & $0.45 \pm 0.11$ & $0.50 \pm 0.08$ & +20.9 & $-4 \S$ \\
\hline Parafetal uterus\| & $0.29 \pm 0.04$ & $0.33 \pm 0.04$ & $0.47 \pm 0.04$ & $+48 \cdot 2^{* *}$ & $-20 \S$ \\
\hline Uterine cervix $\ddagger$ & $0.29 \pm 0.02$ & $0.51 \pm 0.09$ & $0.52 \pm 0.05$ & $+8 \cdot 3$ & $+16 \S$ \\
\hline Ovaries & $0.13 \pm 0.01$ & $2.02 \pm 0.16$ & $2.62 \pm 0.22$ & $+33 \cdot 0^{*}$ & $-2 \S$ \\
\hline Vagina & $0.49 \pm 0.03$ & $1 \cdot 10 \pm 0.33$ & $1.13 \pm 0.24$ & $+21 \cdot 0$ & $-4 \S$ \\
\hline \multicolumn{6}{|c|}{ B. Late gestation $(\mathrm{N}=6)$} \\
\hline Placentas & $17 \cdot 73 \pm 2 \cdot 26$ & $1.70 \pm 0.18$ & $1.09 \pm 0.15$ & $-35 \cdot 6^{* *}$ & $+183^{* *}$ \\
\hline Entire uterus & $14.07 \pm 1.26$ & $0.14 \pm 0.01$ & $0.08 \pm 0.01$ & $-42 \cdot 1^{*}$ & $+246^{* *}$ \\
\hline Uterine horns & $13 \cdot 22 \pm 1 \cdot 32$ & $0.13 \pm 0.01$ & $0.08 \pm 0.01$ & $-38 \cdot 7^{*}$ & $+232^{* *}$ \\
\hline Uterine cervix §ণ & $0.53 \pm 0.08$ & $0.56 \pm 0.09$ & $0.16 \pm 0.03$ & $-70 \cdot 1^{* *}$ & $+615^{* *}$ \\
\hline Ovaries $\div$ & $0.14 \pm 0.01$ & $1.42 \pm 0.28$ & $1 \cdot 23 \pm 0.10$ & -7.0 & $+71^{* *}$ \\
\hline Vagina & $1.03 \pm 0.11$ & $0.55 \pm 0.10$ & $0.21 \pm 0.03$ & $-56 \cdot 1^{*}$ & $+408^{* *}$ \\
\hline \multicolumn{6}{|c|}{ Early gestation $(\mathrm{N}=6)$} \\
\hline Placentas $\ddagger$ & $2 \cdot 16 \pm 0.51$ & $0.20 \pm 0.01$ & $0.15 \pm 0.04$ & $-27 \cdot 2$ & +111 \\
\hline Entire uterus & $1.63 \pm 0.09$ & $0.58 \pm 0.07$ & $0.45 \pm 0.07$ & $-21 \cdot 0^{*}$ & $+93^{*}$ \\
\hline Uterine horns & $1.36 \pm 0.10$ & $0.56 \pm 0.07$ & $0.44 \pm 0.06$ & $-18 \cdot 8$ & $+91^{*}$ \\
\hline Perifetal uterus & $0.91 \pm 0.07$ & $0.62 \pm 0.09$ & $0.41 \pm 0.06$ & $-30 \cdot 5$ & $+143^{*}$ \\
\hline Parafetal uterus $\S$ & $0.52 \pm 0.05$ & $0.38 \pm 0.07$ & $0.47 \pm 0.06$ & $+28 \cdot 0^{* *}$ & +19 \\
\hline Uterine cervix $\S$ & $0.23 \pm 0.03$ & $0.83 \pm 0.17$ & $0.51 \pm 0.12$ & $-36 \cdot 4$ & $+163^{*}$ \\
\hline Ovaries & $0.10 \pm 0.01$ & $1.80 \pm 0.30$ & $2.68 \pm 0.37$ & $+60 \cdot 0^{*}$ & -3 \\
\hline Vagina $\ddagger$ & $0.47 \pm 0.04$ & $0.93 \pm 0.17$ & $0.59 \pm 0.04$ & $-29 \cdot 0$ & +109 \\
\hline
\end{tabular}

Values are mean \pm s.e.m.

${ }^{*} P<0.05 ;{ }^{* *} P<0.01$.

$\dagger \mathbf{N}=7$.

$\mp N=4$.

$\S N=5$.

ๆ Tissue samples contained $<400$ microspheres injected during noradrenaline infusion.

॥ Tissue samples contained $<400$ microspheres from either or both injections. 
Table 2. Distribution of cardiac output to the genital tract of pregnant guinea-pigs before and during infusion of noradrenaline

\begin{tabular}{|c|c|c|c|c|c|}
\hline \multirow{4}{*}{$\begin{array}{c}\text { Stage } \\
\text { of } \\
\text { gestation }\end{array}$} & \multirow[b]{4}{*}{ Organ } & \multicolumn{4}{|c|}{ Noradrenaline infusion dose } \\
\hline & & \multicolumn{2}{|c|}{$1.0 \mu \mathrm{g} / \mathrm{min} / \mathrm{kg}$} & \multicolumn{2}{|c|}{$10 \mu \mathrm{g} / \mathrm{min} / \mathrm{kg}$} \\
\hline & & \multicolumn{2}{|c|}{ Share of cardiac output (\%) } & \multicolumn{2}{|c|}{ Share of cardiac output (\%) } \\
\hline & & Control & Noradrenaline & Control & Noradrenaline \\
\hline & & (8) & (8) & (6) & (6) \\
\hline \multirow{6}{*}{ Late } & Placentas & 11.56 & $10 \cdot 37^{*}$ & 18.08 & $8.55^{* * *}$ \\
\hline & Entire uterus & 0.86 & 0.71 & $1 \cdot 23$ & $0.49^{*}$ \\
\hline & Uterine horns & 0.70 & 0.61 & 1.04 & $0.43^{*}$ \\
\hline & Uterine cervix & 0.15 & $0.09^{* *}$ & $0 \cdot 18$ & $0.03^{*}$ \\
\hline & Ovaries & 0.12 & 0.12 & 0.11 & 0.08 \\
\hline & Vagina & 0.27 & $0 \cdot 17^{* *}$ & 0.36 & $0.09^{*}$ \\
\hline \multirow{9}{*}{ Early } & & (7) & (7) & (6) & (6) \\
\hline & Placentas & $0 \cdot 23$ & 0.24 & 0.36 & $0.20^{*}$ \\
\hline & Entire uterus & 0.57 & 0.49 & 0.76 & $0.35^{* *}$ \\
\hline & Uterine horns & 0.44 & 0.39 & 0.62 & $0.28^{*}$ \\
\hline & Perifetal uterus & 0.37 & 0.31 & 0.47 & $0 \cdot 18^{*}$ \\
\hline & Parafetal uterus & 0.07 & 0.08 & 0.17 & 0.12 \\
\hline & Uterine cervix & 0.12 & 0.08 & 0.14 & $0.06^{* *}$ \\
\hline & Ovaries & 0.20 & $0 \cdot 18$ & $0 \cdot 15$ & 0.13 \\
\hline & Vagina & 0.41 & $0.32^{*}$ & 0.34 & $0.15^{*}$ \\
\hline
\end{tabular}

Values are means for the no. of animals indicated in parentheses.

${ }^{*} P<0.05 ;{ }^{* *} P<0.01$.

During infusion of the larger dose of noradrenaline in late pregnancy, a large increase in vascular resistance occurred throughout the genital tract (Table 1). Blood flow to the placentas, uterus and vagina fell significantly. The decrease in the cervical blood supply was so profound that the number of spheres trapped in the circulation was inadequate to guarantee accurate flow determination (Buckberg et al., 1971). In early pregnancy, the effect on vascular resistance was of lesser magnitude. Blood flow tended to fall, but a significant decrease was registered only for the uterus as a whole. Ovarian vascular resistance remained unaltered, and the increased arterial pressure was reflected in an increased ovarian blood flow. The only significant difference in blood flow responses was between that for the parafetal uterine tissue in early gestation and that of the late pregnant uterus $(P<0.05)$.

When blood flows were expressed as a percentage of the cardiac output, in general, an organ's share of cardiac output fell if its vascular resistance increased during noradrenaline infusion (Table 2). Thus, in late pregnancy, placental blood flow was maintained at the lower rate of infusion, representing a smaller share of the cardiac output. In early pregnancy, when placental vascular resistance was unaltered and blood flow rose, the placentas failed to secure a greater share of the cardiac output.

No redistribution of blood flow within the reproductive tract occurred with either dose of noradrenaline in early or late gestation. No significant difference could be demonstrated between perifetal and parafetal uterine blood flows either initially or during noradrenaline infusion.

\section{Discussion}

These experiments demonstrate that, in the genital tract of the guinea-pig, vascular responses to noradrenaline alter greatly during the course of pregnancy. The noradrenaline was given 
intravenously and changes in blood flow reflect the systemic effect, manifested by the pressor response, as well as local changes in vascular resistance.

In discussing the uterine and placental circulations, it is necessary to differentiate between the direct vasoconstrictor effect of catecholamines and an indirect effect on vascular resistance caused by contraction of the myometrium (Ryan, Clark \& Brady, 1974). In the guinea-pig, no substantial effect of noradrenaline on myometrial contractility is found in late pregnancy, at either of the rates of infusion employed here (A. M. Carter, unpublished data). In early pregnancy, however, the larger dose evokes a sustained contraction. Therefore, whilst the uterotrophic effects of noradrenaline are unlikely to contribute substantially to changes in uteroplacental circulation in late pregnancy, they must be taken into account in early gestation.

The vascular responses of the genital tract were, however, more evident in late gestation, when there was a rise in uteroplacental vascular resistance that was dose-related. During infusion of the smaller dose of noradrenaline this rise was offset by the rise in blood pressure, so that no change in blood flow occurred, whereas at the higher rate of infusion there was a substantial decrease in uterine and placental blood flow. Much of the increase in resistance probably resulted from constriction of the extrinsic uterine arteries. In pregnant guinea-pigs, two thirds of the total uterine vascular resistance is located in these vessels (Moll \& Künzel, 1971), which are known to constrict after the intra-arterial injection of noradrenaline (Egund \& Carter, 1980).

In early pregnancy an augmentation of blood flow was noted in all reproductive organs at the lower rate of noradrenaline infusion, although the increase was significant only for the placental and ovarian tissues. These alterations can be ascribed to the increase in perfusion pressure, since no significant changes occurred in vascular resistance. A similar increase in uterine blood flow was found in near-term sheep after the intravenous injection of 0.1 to $2.0 \mu \mathrm{g}$ noradrenaline $/ \mathrm{kg}$, especially at lower concentrations of the drug (Ladner, Brinkman, Weston \& Assali, 1970). In early pregnant guinea-pigs, uterine vascular resistance increased at the higher rate of infusion, probably wholly or partly due to sustained contraction of the uterus. In either case, the response of the blood vessels is clearly much smaller in early pregnancy, suggesting that a leftward shift of the dose-response curve occurs towards term.

Supersensitivity to noradrenaline and other agents is known to develop when vascular smooth muscle is deprived of its adrenergic innervation (Fleming, McPhillips \& Westfall, 1973). In guinea-pig pregnancy, fluorescent adrenergic nerve fibres disappear entirely from the uterine muscle, although Sjöberg (1967) found that some remain in the small blood vessels of the uterus. The extrinsic uterine arteries certainly retain some innervation, since they are able to release noradrenaline in response to perivascular nervous stimulation (Bell \& Vogt, 1971). However, the amount of transmitter released is variable and becomes very low in the last stages of pregnancy (Bell \& Vogt, 1971). The supersensitivity caused by depletion of transmitter stores is non-specific and due to post-junctional changes, including a decrease in the resting membrane potential of the smooth muscle cells (Gerthoffer, Fedan, Westfall, Goto \& Fleming, 1979). A more specific effect on the sensitivity of effector cells to noradrenaline, due to reduced neuronal uptake, is known to result from surgical or chemical sympathectomy (Fleming et al., 1973), and specific and non-specific supersensitivity could result from decreased adrenergic influence on uterine blood vessels with advancing pregnancy.

Despite the striking changes in uterine innervation, it may be unwise to interpret the increased response to noradrenaline solely in terms of denervation supersensitivity. The vagina retains its adrenergic innervation during pregnancy (Bell \& Malcolm, 1978) and some adrenergic nerves also persist in the cervical region of the uterus (Thorbert et al., 1978). In both tissues, vascular resistance increased greatly during noradrenaline infusion, and they were the only regions of the genital tract to undergo a significant reduction in blood flow at the lower rate of infusion in late gestation.

Ovarian vascular resistance was little affected by noradrenaline and a significant and 
dose-related increase in ovarian blood flow was noted in early pregnancy. This is consistent with the view that ovarian blood flow lacks autoregulation and is dependent on blood pressure changes. In pseudopregnant rabbits, there is a linear relationship between increases in arterial blood pressure and ovarian blood flow (Janson, 1974), a finding that agrees well with the observed response to noradrenaline of early pregnant guinea-pigs.

Anaesthesia is believed to interfere with and partly inhibit the responses of the adrenergic receptor (Brinkman, Moffid \& Assali, 1974). The doses of noradrenaline used in this study are considerably larger than those required to obtain similar effects on uterine and placental blood flow in the chronically prepared sheep (Rosenfeld \& West, 1976). This difference in sensitivity might be due to the influence of barbiturate anaesthesia, although an alternative explanation can be advanced, based on the difference in vascular morphology between the haemomonochorial and syndesmochorial placental types. To resolve this question, a study of unanaesthetized pregnant guinea-pigs is required, and is presently being attempted in this laboratory.

This work was supported by the Danish Medical Research Council. L.M. was the recipient of a Graduate Fellowship under the Nordic Research Courses programme.

\section{References}

Alm, P., Björklund, A., Owman, Ch. \& Thorbert, G. (1979) Tyrosine hydroxylase and DOPA decarboxylase activities in the guinea-pig uterus: further evidence for functional adrenergic denervation in association with pregnancy. Neuroscience 4, 145-154.

Bell, C. \& Malcolm, S.J. (1978) Observations on the loss of catecholamine fluorescence from intrauterine adrenergic nerves during pregnancy in the guinea-pig. J. Reprod. Fert. 53, 51-58.

Bell, C. \& Vogt, M. (1971) Release of endogenous noradrenaline from an isolated muscular artery. $J$. Physiol., Lond. 215, 509-520.

Brinkman, C.R., Moffid, M. \& Assali, N.S. (1974) Circulatory shock in pregnant sheep. III. Effects of hemorrhage on uteroplacental and fetal circulation and oxygenation. Am. J. Obstet. Gynec, 118, 77-90.

Buckberg, G.D., Luch, J.C., Payne, D.B., Hoffman, J.I.E., Archie, J.P. \& Fixler, D.E. (1971) Sources of errors in measuring regional blood flow with radioac tive microspheres. J. appl. Physiol. 31, 598-604.

Draper, R.L. (1920) The prenatal growth of the guinea pig. Anat. Rec. 18, 369-392.

Egund, N. \& Carter, A.M. (1980) Adrenergic and cholinergic responses in the uteroplacental vascular bed of the guinea pig. Acta radiol. diagn. 21, 387-396.

Fleming, W.W., McPhillips, J.J. \& Westfall, D.P. (1973) Postjunctional supersensitivity and subsensitivity of excitable tissues to drugs. Ergeb. Physiol. 68, 55-119.

Gerthoffer, W.T., Fedan, J.S., Westfall, D.P., Goto, K. \& Fleming, W.W. (1979) Involvement of the sodiumpotassium pump in the mechanism of postjunctional supersensitivity of the vas deferens of the guinea pig. J. Pharmacol. exp. Ther. 210, 27-36.

Janson, P.O. (1974) Ovarian Blood Flow. Methodological and Functional Studies in the Rabbit. Gothenburg.
Ladner, C., Brinkman, C.R., Weston, P. \& Assali, N.S. (1970) Dynamics of uterine circulation in pregnant and nonpregnant sheep. Am. J. Physiol. 218. 257. 263.

Mårtensson, L., Sjöquist, P.-O., Bjellin, L. \& Carter, A.M. (1979) Myoendothelial and placental blood flow responses to ritodrine infusions in the guinea pig. Am. J. Obstet. Gynec. 135, 318-321.

Moll, W. \& Künzel, W. (1971) Blood pressures in the uterine vascular system of anaesthetized pregnant guinea pigs. Pflügers Arch. 330, 310-322.

Owman, Ch., Rosengren, E., Sjöberg, N.-O. \& Thorbert, G. (1975) Variations in the level of uterine norepinephrine during pregnancy in the guinea pig. $A m . J$. Obstet. Gynec. 122, 961-964.

Rosenfeld, C.R. \& West, J. (1976) Circulatory response to systemic infusion of norepinephrine in the pregnant ewe. Am. J. Obstet. Gynec. 127, 376-383.

Ryan, M.J., Clark, K.E. \& Brady, M.J. (1974) Neurogenic and mechanical control of the canine uterine vascular resistance. Am. J. Physiol. 227. $547-555$.

Sjöberg, N.-O. (1967) The adrenergic transmitter of the female reproductive tract: Distribution and functional changes. Acta physiol. scand., Suppl. 305, $1-32$.

Sjöquist, P.-O.B., Bjellin, L. \& Carter, A.M. (1977) Blood flow to the genital tract of oestrous and dioestrous guinea-pigs. J. Reprod. Fert. 51, 83-86.

Thorbert, G., Alm, P., Owman, Ch., Sjöberg, N.-O. \& Sporrong, B. (1978) Regional changes in structural and functional integrity of myometrial adrenergic nerves in pregnant guinea-pig, and their relationship to the localization of the conceptus. Acta physiol. scand. 103, 120-131.

Towell, M.E. \& Liggins, G.C. (1976) The effect of labour on uterine blood flow in the pregnant ewe. $Q . J$ Physiol. 81, 23-33. 